\title{
Box-loop technique in the management of complex elbow instability: a prospective controlled trial
}

\author{
Giovanni Vicenti ${ }^{1}$ \\ Giuseppe Solarino ${ }^{1}$ \\ Massimiliano Carrozzo ${ }^{1}$ \\ Davide Bizzoca ${ }^{1}$ \\ Alessandro Marinelli2 \\ Roberto Rotini ${ }^{2}$ \\ Biagio Moretti ${ }^{1}$ \\ 1 Department of Neuroscience and Organs of Sense, \\ Orthopedic Section, Faculty of Medicine and Surgery, \\ University of Bari, Bari, Italy \\ 2 Shoulder and Elbow Unit, Rizzoli Orthopaedic Insti- \\ tute, Bologna, Italy
}

Corresponging author:

Massimiliano Carrozzo

Department of Neuroscience and Organs of Sense, Orthopedic Section, Faculty of Medicine and Surgery, University of Bari

Piazza Giulio Cesare 11

70124 Bari, Italy

Tel.: +39 3420063677

E-mail: doc.mcarrozzo@gmail.com

\section{Summary}

Introduction: Chronic elbow instability is a disable complication. This prospective study reports our experience with the box-loop reconstruction technique, compared with traditional Lateral Collateral Ligament (LCL) and eventual Medial Collateral Ligament (MCL) reconstruction, showing its functional outcome at 12-month follow-up.

Methods: From January 2013 to February 2017, 27 patients with complex elbow instability were recruited. Group-A patients were managed using box-loop technique; in Group-B patients LCL reconstruction was performed and MCL lesions were always intraoperatively tested, under fluoroscopy, and eventually treated. Clinical evaluations were performed at baseline (TO) and at 1month (T1), 6-month (T2) and 12-month (T3) follow-up. X-rays were performed at TO and T3. Intergroup and intragroup variability was assessed. Results: In all the patients, an improvement of both the range of movement and the joint stability was observed after surgery. The mean increase in flexion-extension arch was $52^{\circ}$ in Group-A patients at 12-month follow-up. A significant improvement $(p<0.05)$ of Mayo Elbow Performance Score, Oxford Elbow Scores and Visual Analogue Scale was observed at 12-month follow-up in both groups.

Conclusion: Box-loop technique revealed safe and effective in the management of multidirectional elbow instability.

Level of evidence: IV, Cases Series.

KEY WORDS: elbow chronic instability, box-loop reconstruction technique, elbow dislocation, circumferential graft technique, lateral collateral ligament, medial collateral ligament.

\section{Introduction}

Elbow dislocations are the second most common major joint dislocations in adults, with a reported annual incidence of $5.21 / 100,000$ people in the USA ${ }^{1}$.

Simple elbow dislocations, without associated fractures, account for $50-60 \%$ of elbow dislocations and are generally non-operatively managed, with short-term immobilization followed by early functional therapy ${ }^{2-4}$. Recent studies, nonetheless, have shown a complex damage of capsuloligamentous even in simple dislocations, thus affecting the whole joint stability ${ }^{4-6}$.

Elbow chronic instability is a disable complication, presenting as recurrent joint subluxations or dislocations, which can be observed in elbow dislocations with ligamentous insufficiency $4,7,8$.

Several reconstructive techniques of the Lateral Collateral Ligament (LCL) complex and the Medial Collateral Ligament (MCL) complex have been described to treat lateral or medial elbow instability, respectively $9-13$

In some cases, however, a multidirectional instability can be depicted, thus the reconstruction of both the $\mathrm{LCL}$ and the MCL is required. Finkbone and O'Driscoll ${ }^{14}$ have recently described the box-loop reconstruction technique, a less invasive method which reconstructs the entire collateral ligament complex, using a single circumferential tendon graft.

This prospective controlled study reports the outcome of the box-loop reconstruction technique, compared with $L C L$ and eventual MCL reconstruction, at 12month follow-up. 


\section{Material and methods}

\section{Patients selection}

From January 2013 to February 2017, 27 patients referring to our Department with chronic complex elbow instability were recruited.

Patients were then divided into two groups, according to the surgical procedure performed to obtain the elbow stability. Group-A patients were managed using box-loop technique, between September 2015 and February 2017. In Group-B patients, on the other hand, LCL reconstruction was performed, while suspected MCL lesions were always intraoperatively tested, under fluoroscopy, and eventually treated, between January 2013 and August 2015. A 2-0 FiberWire $^{\mathrm{TM}}$ (Arthrex, Naples, FL, USA) was used to perform the LCL and, eventually, the MCL complex reconstruction.

Postoperatively, in Group-A patients the elbow was immobilized in a cast for 2 weeks, followed by 4 weeks in an articular brace, in order to allow gentle active and active-assistive exercises. The brace was then progressively dismissed, on the basis of the patient's history and clinical outcome.

In Group-B patients, the elbow was immobilized in extension in a splint for 48 hours, followed by 5 weeks in an articular brace, which was progressively dismissed, depending on the patient's history and clinical outcome.

All the patients gave informed consent before enrolment. The study was conducted according to international standards ${ }^{15}$.

\section{Box-loop technique description}

All the box-loop reconstructions were performed by the same surgeon (G.V.) according to the technique description by Finkbone and O'Driscoll ${ }^{14}$ (Figs. 1, 2). Two different medial and later surgical incisions were generally performed; when concomitant surgery was needed, i.e. radial head fixation or arthroplasty, a posterolateral Kocher approach was used. An autologous gracilis graft was used to perform the circumferential reconstruction.

On the medial side, with the elbow flexed at $90^{\circ}$, the distal dissection is made by splitting, at its origin, the common flexor-pronator tendon. Then, the origin of the $\mathrm{MCL}$, on the anterior-inferior margin of the epicondyle, and its insertion, on the sublime tubercle of the ulna, are depicted. A 3.2- $\mathrm{mm}$ drill hole, is performed into the anterior inferior margin of the epicondyle and into the ulna, just a few millimetres distal to the MCL insertion. Care should be taken to not drill deeper, at this side, since the drilling line must be definitively chosen, after the identification of the corresponding lateral point.

On the lateral side, the deep dissection is performed through the anconaeus interval; the interosseous vessels are cauterized. The LCL complex, together with the capsule, is splint longitudinally toward the supinator crest tubercle. The isometric point on the lateral condyle, which must be equidistant from the anterior, proximal and distal margins of the capitellum, is assessed. A 3.2-mm drill hole is performed there and into the ulna just a few millimetres posterior to the supinator crest tubercle. Then, a target end of a drill

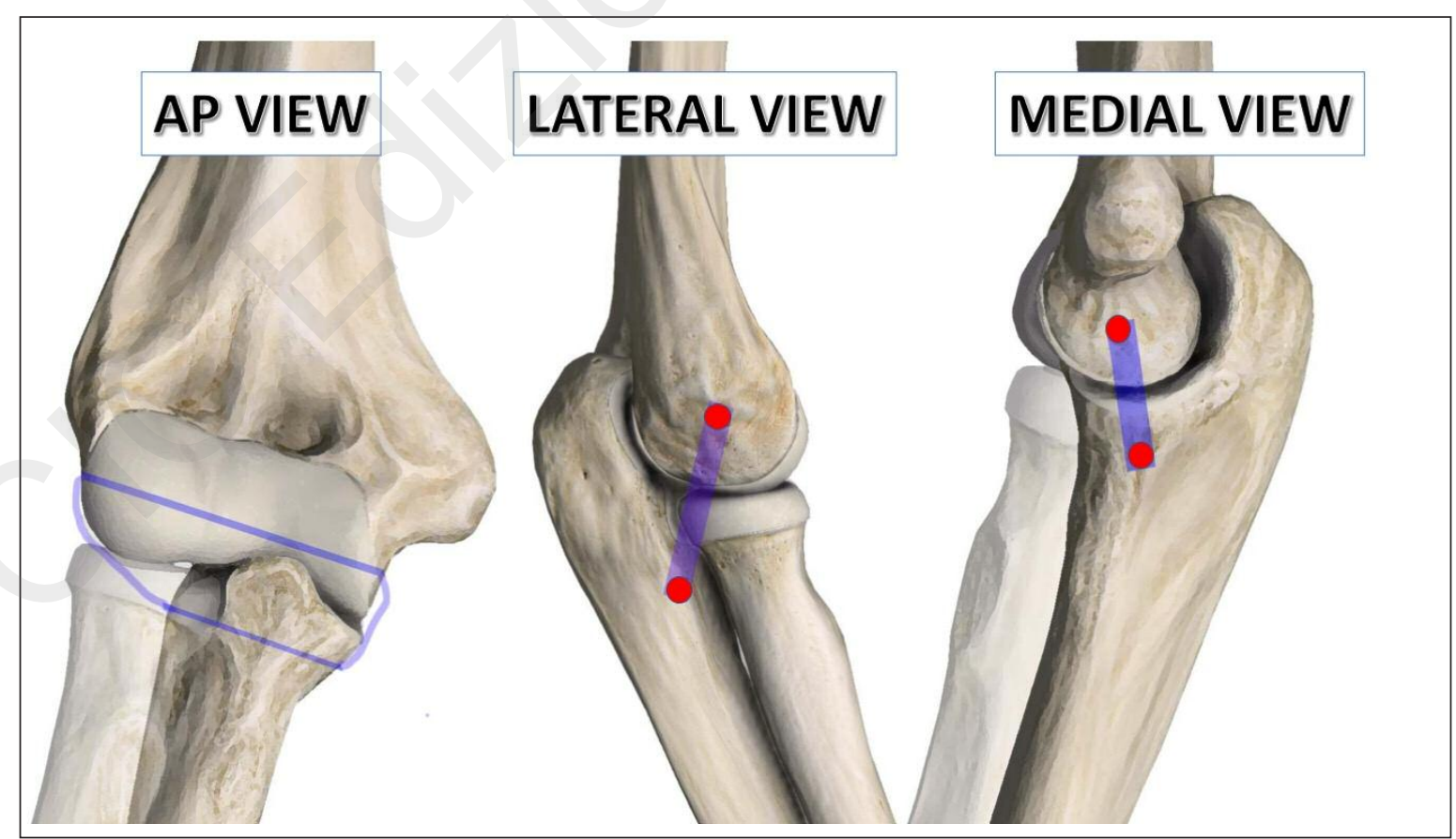

Figure 1. Box-loop technique, as described by Finkbone and O'Driscoll. AP view; Lateral View; Medial view. The entry point of the drill bit where to make the tunnels are indicated in red. 

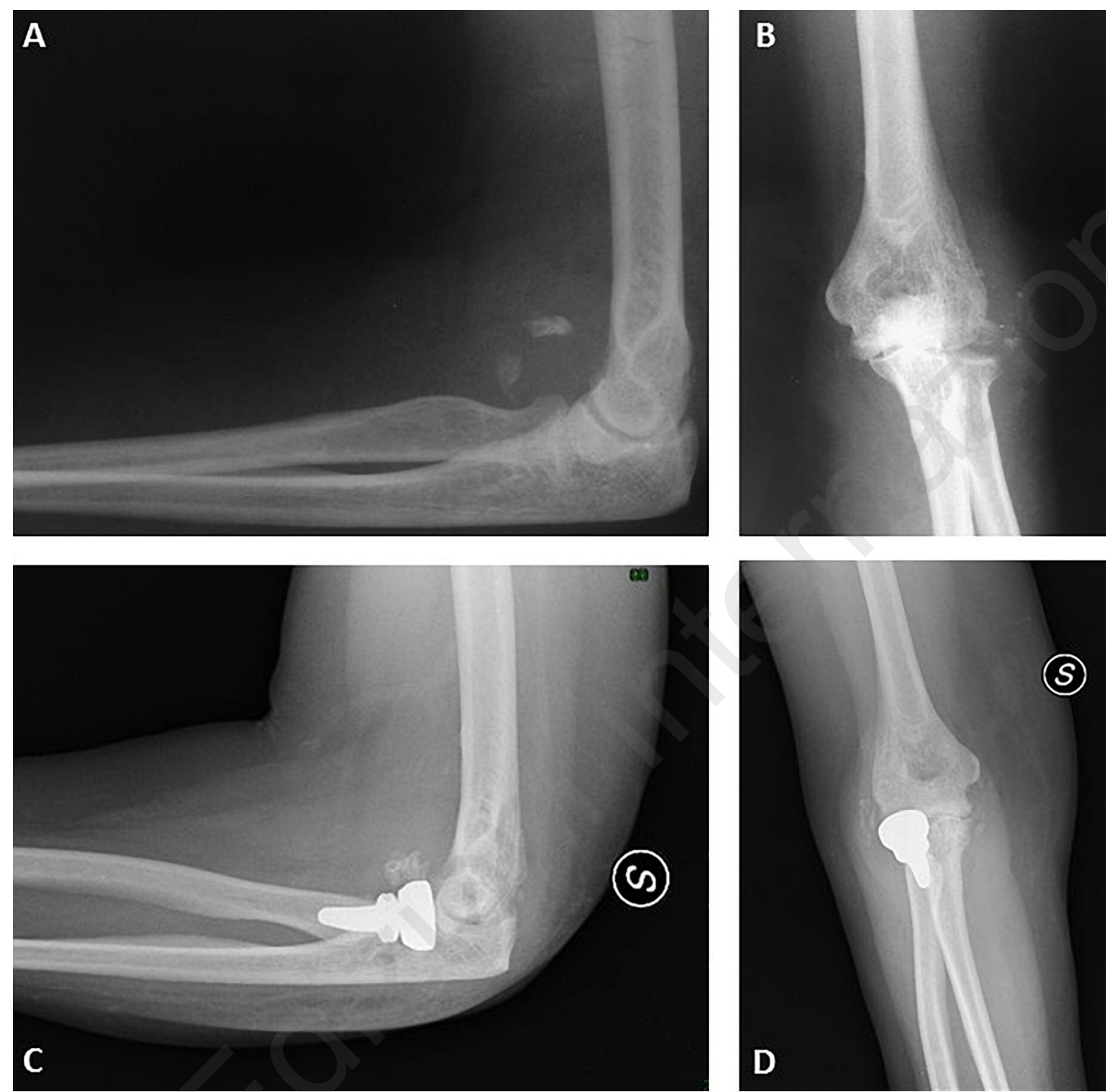

Figure 2. Preoperative (A, B) and 1-month follow-up (C, D) radiographs of case A1.

guide is placed into the corresponding medial hole and, starting from the lateral side, about $60 \%$ of the humerus lateral-medial distance is drilled. The same procedure is made into the ulnar hole and, after that, on the medial side holes.

A split gracilis autograft is prepared using a 2-0 FiberWire $^{\mathrm{TM}}$ (Arthrex, Naples, FL, USA) stitch. The graft is passed through the humerus and looped through the ulna twice. Finally, the capsule and the residual ligament tissue are sutured and the graft is tensioned.

\section{Outcome evaluation}

Functional outcomes were assessed at baseline $\left(T_{0}\right)$ and at 1-month $\left(T_{1}\right), 6$-months $\left(T_{2}\right)$ and 12-months $\left(\mathrm{T}_{3}\right)$ after surgery, by the OES, the MEPS and the $\mathrm{Vi}$ sual Analogue Scale (VAS).
Clinical examination at each follow-up included: range of motion evaluation; pivot shift test; posterolateral rotatory drawer test, varus and valgus stress tests in complete extension and $30^{\circ}$ of flexion. Radiological evaluation, including anteroposterior and lateral views of the elbow, was performed after surgery and at 12-month follow-up ( $\left.\mathrm{T}_{3}\right)$.

\section{Statistical analysis}

Statistical analysis was performed using the SPSS $B$ 11.0 software (SPSS Inc., Chicago, IL, USA). The paired $t$ test was used to assess the variability within groups; the unpaired t test was performed to evaluate the intergroup variability. The tests were two-tailed with a confidence level of $5 \%$. 


\section{Results}

The patients' characteristics are summarized in Table I. Twelve patients (8 males, 4 females; mean age 45.75; range 19-67) were managed with box-loop reconstruction technique (Group-A), whereas 15 patients (10 males, 5 females; mean age 46.93; range 21-65) were treated with traditional LCL and eventually MCL reconstruction (Group-B, Tab. I).

In Group-A patients, radial head arthroplasty (Evolve $^{\mathrm{TM}}$ Proline, Wright, Memphis, Tennessee, USA) was previously performed in 3 patients out of
$12(25 \%)$, while 1 patient out of 12 (8.33\%) had already performed a radial head open reduction and internal fixation (ORIF).

In Group-B patients, radial head arthroplasty (Evolve $^{\mathrm{TM}}$ Proline, Wright, Memphis, Tennessee, USA) was previously performed in 3 patients out of $15(20 \%)$, and 3 patients out of $15(20 \%)$ had already performed a radial head ORIF.

Table II shows the clinical outcomes at 12-month follow-up compared with baseline (Paired-t test). In all patients, an improvement of range of motion was observed postoperatively: the mean flexion-extension

Table I. Patient demographics.

\begin{tabular}{|c|c|c|c|c|c|c|c|}
\hline & & & & & Group-A & & 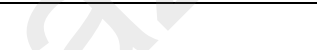 \\
\hline Case & Age & Sex & Side & Job & Comorbidities & Diagnosis & Prior surgery \\
\hline A1 & 63 & Female & Right & Housewife & $\begin{array}{l}\text { Hypertension; } \\
\text { Hypothyroidism }\end{array}$ & $\begin{array}{c}\text { Chronic instability } \\
\text { after terrible triad } \\
\text { injury }\end{array}$ & $\begin{array}{l}\text { Radial head arthroplasty } \\
\text { Coronoid pull-out }\end{array}$ \\
\hline A2 & 44 & Male & Right & Bricklayer & - & $\begin{array}{l}\text { Chronic instability } \\
\text { with coronoid non- } \\
\text { union }\end{array}$ & - \\
\hline A3 & 48 & Female & Right & Seamstress & $\begin{array}{c}\text { Smoker; } \\
\text { Diabetes Mellitus }\end{array}$ & $\begin{array}{l}\text { Chronic instability } \\
\text { with coronoid and } \\
\text { radial head non- } \\
\text { union }\end{array}$ & Radial head arthroplasty \\
\hline A4 & 27 & Male & Left & Farmer & Smoker & $\begin{array}{l}\text { Chronic instability } \\
\text { after multiple } \\
\text { dislocations }\end{array}$ & - \\
\hline A5 & 59 & Male & Left & Chef & - & $\begin{array}{c}\text { Chronic instability } \\
\text { after terrible triad } \\
\text { injury }\end{array}$ & ORIF of radial head \\
\hline A6 & 38 & Male & Right & Farmer & - & $\begin{array}{l}\text { Chronic instability } \\
\text { after multiple } \\
\text { dislocations }\end{array}$ & - \\
\hline A7 & 45 & Male & Right & Bricklayer & $\begin{array}{c}\text { Smoker; } \\
\text { Dyslipidaemia }\end{array}$ & Chronic instability & - \\
\hline A8 & 43 & Female & Left & Teacher & Smoker & $\begin{array}{c}\text { Chronic instability } \\
\text { after terrible triad } \\
\text { injury }\end{array}$ & $\begin{array}{l}\text { Radial head arthroplasty } \\
\text { Coronoid pull-out }\end{array}$ \\
\hline A9 & 55 & Female & Right & Housewife & - & Chronic instability & - \\
\hline A10 & 19 & Male & Left & Farmer & - & Chronic instability & - \\
\hline A11 & 41 & Male & Left & Plumber & $\begin{array}{c}\text { Diabetes } \\
\text { Mellitus }\end{array}$ & Chronic instability & - \\
\hline A12 & 67 & Male & Right & - & - & $\begin{array}{c}\text { Chronic instability } \\
\text { after terrible triad } \\
\text { injury }\end{array}$ & Coronoid pull-out \\
\hline
\end{tabular}




\begin{tabular}{|c|c|c|c|c|c|c|c|c|}
\hline \multicolumn{9}{|c|}{ Group-B } \\
\hline Case & $\begin{array}{c}\mathrm{Ag} \\
\mathrm{e}\end{array}$ & Sex & Side & Job & Comorbidities & Diagnosis & Surgery & Prior surgery \\
\hline B1 & 21 & Male & Right & Student & - & $\begin{array}{l}\text { Chronic instability } \\
\text { after elbow } \\
\text { dislocation }\end{array}$ & LCL/MCL & - \\
\hline B2 & 48 & Male & Left & Farmer & - & Chronic instability & LCL/MCL & - \\
\hline B3 & 43 & Female & Right & Nurse & $\begin{array}{c}\text { Smoker; } \\
\text { Hypertension }\end{array}$ & $\begin{array}{l}\text { Chronic instability } \\
\text { after terrible triad } \\
\text { injury }\end{array}$ & LCL/MCL & $\begin{array}{l}\text { ORIF of radial } \\
\text { head }\end{array}$ \\
\hline B4 & 54 & Male & Right & Teacher & $\begin{array}{c}\text { Smoker; } \\
\text { Diabetes Mellitus }\end{array}$ & $\begin{array}{l}\text { Chronic instability } \\
\text { after multiple } \\
\text { dislocations }\end{array}$ & LCL/MCL & - \\
\hline B5 & 65 & Female & Right & Housewife & $\begin{array}{l}\text { Hypothyroidism; } \\
\text { Diabetes } \\
\text { Mellitus; } \\
\text { Hypertension }\end{array}$ & $\begin{array}{l}\text { Chronic instability } \\
\text { after terrible triad } \\
\text { injury }\end{array}$ & LCL & $\begin{array}{l}\text { ORIF of radial } \\
\text { head } \\
\text { Coronoid pull- } \\
\text { out }\end{array}$ \\
\hline B6 & 51 & Male & Left & Employer & - & $\begin{array}{l}\text { Chronic instability } \\
\text { after dislocation }\end{array}$ & LCL & - \\
\hline B7 & 44 & Male & Right & Physician & & Chronic instability & LCL/MCL & - \\
\hline B8 & 38 & Male & Left & Bricklayer & Smoker & $\begin{array}{l}\text { Chronic instability } \\
\text { after terrible triad } \\
\text { injury }\end{array}$ & LCL/MCL & $\begin{array}{l}\text { Radial head } \\
\text { arthroplasty }\end{array}$ \\
\hline B9 & 42 & Female & Left & Teacher & - & $\begin{array}{l}\text { Chronic instability } \\
\text { after terrible triad } \\
\text { injury }\end{array}$ & LCL/MCL & $\begin{array}{c}\text { Radial head } \\
\text { arthroplasty } \\
\text { Coronoid pull- } \\
\text { out }\end{array}$ \\
\hline B10 & 56 & Male & Right & Bricklayer & - & $\begin{array}{l}\text { Chronic instability } \\
\text { after dislocation }\end{array}$ & LCL & - \\
\hline B11 & 47 & Male & Right & Farmer & - & $\begin{array}{l}\text { Chronic instability } \\
\text { after multiple } \\
\text { dislocations }\end{array}$ & LCL/MCL & - \\
\hline B12 & 61 & Female & Left & Plumber & $\begin{array}{c}\text { Smoker; } \\
\text { Hypertension }\end{array}$ & $\begin{array}{l}\text { Chronic instability } \\
\text { after terrible triad } \\
\text { injury }\end{array}$ & LCL/MCL & $\begin{array}{l}\text { Radial head } \\
\text { arthroplasty }\end{array}$ \\
\hline B13 & 55 & Male & Right & Employer & - & $\begin{array}{l}\text { Chronic instability } \\
\text { after terrible triad } \\
\text { injury }\end{array}$ & LCL & $\begin{array}{l}\text { ORIF of radial } \\
\text { head } \\
\text { Coronoid pull- } \\
\text { out }\end{array}$ \\
\hline B14 & 32 & Female & Right & Hostess & - & $\begin{array}{l}\text { Chronic instability } \\
\text { after dislocation }\end{array}$ & LCL & - \\
\hline B15 & 47 & Male & Right & Policeman & - & $\begin{array}{l}\text { Chronic instability } \\
\text { after multiple } \\
\text { dislocations }\end{array}$ & LCL & - \\
\hline
\end{tabular}


Table II. Physical Examination Results: intragroup variability (Paired t-test).

\begin{tabular}{|c|c|c|c|c|c|c|c|c|}
\hline \multicolumn{9}{|c|}{ Group-A } \\
\hline & \multicolumn{2}{|c|}{ Preoperative } & \multicolumn{3}{|c|}{ Postoperative } & \multicolumn{3}{|c|}{ Stability* (Pre/post) $^{*}$} \\
\hline & Mean F/E & Mean P/S & Mean F/E & Mean P/S & & Varus & Valgus & $\begin{array}{c}\text { Posterolatera } \\
\text { I rotatory }\end{array}$ \\
\hline Mean & $110.5^{\circ} / 42^{\circ}$ & $71^{\circ} / 80^{\circ}$ & $147^{\circ} / 0^{\circ}$ & $87^{\circ} / 86^{\circ}$ & $52.5^{\circ}$ & $2 / 0$ & $1 / 0$ & $3 / 0$ \\
\hline \multirow[t]{4}{*}{$p$} & - & - & 0.01 & 0.01 & 0.01 & 0.01 & 0.01 & 0.01 \\
\hline & & & \multicolumn{3}{|c|}{ Group-B } & & & \\
\hline & \multicolumn{2}{|c|}{ Postoperative } & \multicolumn{3}{|c|}{ Preoperative } & \multicolumn{3}{|c|}{ Stability* (Pre/post) } \\
\hline & Mean F/E & Mean P/S & Mean F/E & Mean P/S & & Varus & Valgus & $\begin{array}{c}\text { Posterolatera } \\
\text { I rotatory }\end{array}$ \\
\hline Mean & $106.4^{\circ} / 40^{\circ}$ & $70^{\circ} / 80^{\circ}$ & $145.3^{\circ} / 10^{\circ}$ & $88^{\circ} / 85^{\circ}$ & $54.3^{\circ}$ & $1 / 0$ & $2 / 0$ & $3 / 0$ \\
\hline$p$ & - & - & 0.01 & 0.01 & 0.01 & 0.01 & 0.01 & 0.01 \\
\hline
\end{tabular}

*stability grading: 0 , none; 1 , mild laxity with end point; 2 , moderate laxity with end point; 3 , gross instability.

Table III. Functional outcomes: intra-group variability (Paired t-test).

\begin{tabular}{|c|c|c|c|c|c|c|c|c|c|c|c|c|}
\hline & \multicolumn{12}{|c|}{ Group-A } \\
\hline & \multicolumn{3}{|c|}{ Baseline } & \multicolumn{3}{|c|}{ 1-month follow-up } & \multicolumn{3}{|c|}{ 6-month follow-up } & \multicolumn{3}{|c|}{ 12-month follow-up } \\
\hline & MEPS & OES & VAS & MEPS & OES & VAS & MEPS & OES & VAS & MEPS & OES & VAS \\
\hline Mean \pm SD & $45 \pm 12.6$ & $22 \pm 6.4$ & $6.5 \pm 2$ & $66.2 \pm 7.8$ & $31.2 \pm 4.7$ & $2 \pm 1.8$ & $68.6 .4 \pm 5.7$ & $747.4 \pm 5.2$ & $1 \pm 0.5$ & $72.3 \pm 4.5$ & $51.5 \pm 3.4$ & $1 \pm 0.2$ \\
\hline \multirow[t]{4}{*}{$p$} & - & - & - & 0.01 & 0.022 & 0.009 & 0.004 & 0.006 & 0.001 & 0.002 & 0.003 & 0.001 \\
\hline & \multicolumn{9}{|c|}{ Group-B } & & & \\
\hline & \multicolumn{3}{|c|}{ Baseline } & \multicolumn{3}{|c|}{ 1-month follow-up } & \multicolumn{3}{|c|}{ 6-month follow-up } & \multicolumn{3}{|c|}{ 12-month follow-up } \\
\hline & MEPS & OES & VAS & MEPS & OES & VAS & MEPS & OES & VAS & MEPS & OES & VAS \\
\hline Mean \pm SD & $44 \pm 9.4$ & $23 \pm 7.4$ & $5.7 \pm 3$ & $64.5 \pm 8.5$ & $29.5 \pm 7.5$ & $3.4 \pm 0.76$ & $66.5 \pm 5.4$ & $44.6 \pm 4.3$ & $\overline{1.2 \pm 0.4}$ & $65.5 \pm 3.4$ & $53.4 \pm 4.65$ & $1.3 \pm 0.4$ \\
\hline$p$ & - & & - & 0.02 & 0.032 & 0.005 & 0.002 & 0.004 & 0.001 & 0.001 & 0.002 & 0.001 \\
\hline
\end{tabular}

MEPS: Mayo Elbow Performance Score; OES: Oxford Elbow Score; VAS: Visual Analogue Scale; SD=Standard Deviation

arch improvement was $52.5^{\circ}$, in Group-A patients, and $54.3^{\circ}$, in Group-B patients (Tab. II). All the joints resulted stable after surgery in Group-A, while in Group-B 1 patient out of $15(6.67 \%)$ needed a re-intervention.

Table III summarizes the functional outcomes recorded at each follow-up, compared with baseline in both groups. A significant improvement of OES, MEPS and VAS was recorded at 1-month follow-up in both groups. Two patients out of 12 in Group-A still reported a mild elbow pain at 1-month follow-up; a significant pain reduction, however, was observed at the following follow-ups.

Table IV compares the functional outcomes between the two groups at 12-month follow-up (Unpaired-ttest). No significant differences between groups were observed (Tab. IV).

Radiographs showed no instability signs in all elbow joints (Fig. 2). In Group-A, only 1 joint out of 12 , showed mild degenerative joint changes at 12-month follow-up (Fig. 3).

\section{Discussion}

Chronic elbow instability is a disabling pathology, which may cause chronic pain, feelings of instability, recurrent joint subluxation or dislocation and movement limitations, thus seriously affecting the patient's daily routine ${ }^{16-18}$. Two different circumferential graft techniques have been recently described by Finkbone and O'Driscoll ${ }^{14}$ and by van Riet et al. ${ }^{19,20}$, to treat the combined medial and lateral insufficiency observed in multidirectional elbow instability.

The box-loop reconstruction technique ${ }^{14}$ is a quick, easy and safe procedure; therefore, it has become 
Table IV. Functional outcomes: inter-group variability at 12-month follow-up (Unpaired t-test).

\begin{tabular}{|c|c|c|c|c|c|c|c|c|}
\hline \multicolumn{3}{|c|}{ MEPS } & \multicolumn{3}{|c|}{ OES } & \multicolumn{3}{|c|}{ VAS } \\
\hline Group-A & Group-B & $p$ & Group-A & Group-B & $p$ & Group-A & Group-B & $p$ \\
\hline $72.3 \pm 4.5$ & $65.5 \pm 3.4$ & 0.082 & $51.5 \pm 3.4$ & $53.4 \pm 4.65$ & 0.0993 & $1.3 \pm 0.4$ & $1.3 \pm 0.4$ & 0,985 \\
\hline
\end{tabular}

MEPS: Mayo Elbow Performance Score; OES: Oxford Elbow Score; VAS: Visual Analogue Scale; SD=Standard Deviation

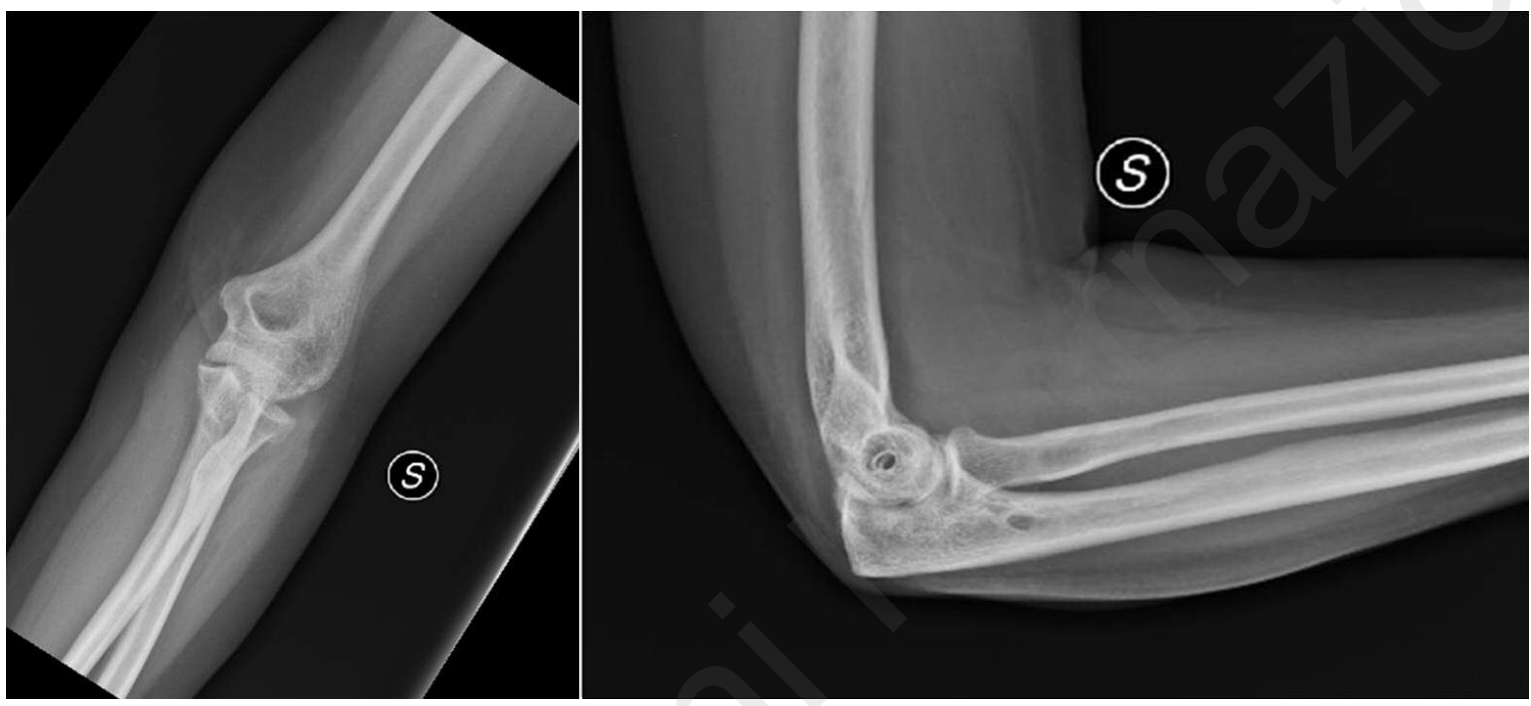

Figure 3. 12-month follow-up radiographs of case A5: note the degenerative changes of the elbow.

our preferred technique for the management of multidirectional instable elbow. This paper reports our experience with this circumferential grafting technique. This is, to the Authors' knowledge, the first prospective controlled study conducted on patients undergoing the box-loop reconstruction.

In the current study, the box-loop reconstruction revealed effective in the treatment of elbow instability: all the joints appeared clinically stable and no further dislocations were observed during follow-up in Group-A patients. In all the patients treated with box-loop technique, elbow pain, recorded as VAS, significantly reduced at follow-ups, thus allowing a great improvement of the elbow range of moment. All these findings had a positive impact on the patients' activities of daily living, as revealed by the significant improvement of OES and MEPS scores at follow-up (Tab. III).

Similar data were reported in a retrospective study by Finkbone and O'Driscoll ${ }^{14}$, who described the outcomes of the box-loop reconstruction technique in 14 patients, with an average follow-up of 64 months. These Authors reported in only 1 patient out of 14 a delayed-onset ulnar neuropathy, which needed an ulnar nerve transposition on postoperative day 12 .

Hackl et al. ${ }^{3}$, in an in vitro study, compared the boxloop reconstruction with the conventional MC and
LCL reconstruction techniques. They concluded that circumferential graft technique described by Finkbone and O'Driscoll ${ }^{14}$ provides equal elbow joint stability, compared with conventional techniques, but it shows a superior biomechanical profile with respect to graft stiffness. This in vitro finding is consistent with the data observed in our study: in all the patients, an increased range of movement was observed, without compromising the whole joint stability. Furthermore, no significant clinical differences between groups were observed at 12-month follow-up in this study.

The sample size is a limitation of this study. Our findings, however, confirm the data reported by Finkbone and O'Driscoll ${ }^{14}$, showing the excellent short-terms outcomes of box-loop reconstruction technique.

Future studies with larger samples and a longer follow-up will be needed to better define the advantages of this surgical technique. All the patients recruited for the current study will undergo a longer follow-up to assess the long-term efficacy of the box-loop reconstruction technique.

\section{Conflicts of interest}

The Authors declare no conflicts of interest concerning this article. 


\section{References}

1. Stoneback JW, Owens BD, Sykes J, Athwal GS, Pointer L, Wolf JM. Incidence of elbow dislocations in the United States population. J Bone Joint Surg Am. 2012;94:240-245.

2. Ahmed I, Mistry J. The Management of Acute and Chronic Elbow Instability. Orthop Clin North Am. 2015 Apr;46(2):271-280.

3. Hackl M, Heinze N, Wegmann K, Lappen S, Leschinger T, Burkhart KJ, Scaal M, Müller LP. The circumferential graft technique for treatment of multidirectional elbow instability: a comparative biomechanical evaluation. J Shoulder Elbow Surg. 2016 Jan;25(1):127-135.

4. Hackl M, Beyer F, Wegmann K, Leschinger T, Burkhart KJ, Müller LP.The treatment of simple elbow dislocation in adultsa systematic review and meta-analysis. Dtsch Arztebl Int 2015;112:311-319.

5. Fitzpatrick MJ, Diltz M, McGarry MH, Lee TQ. A new fracture model for "terrible triad" injuries of the elbow: influence of forearm rotation on injury patterns. J Orthop Trauma. 2012;26: 591-659.

6. Gregory B, Nyland J. Medial elbow injury in young throwing athletes. Muscles Ligaments Tendons J. 2013 Apr-Jun;3(2): 91-100.

7. Micic I, Kim SY, Park IH, Kim PT, Jeon IH. Surgical management of unstable elbow dislocation without intra-articular fracture. Int Orthop. 2009;33:1141-1147.

8. Duckworth AD, Ring D, Kulijdian A, McKee MD. Unstable elbow dislocations. J Shoulder Elbow Surg. 2008;17:281-286.

9. Cheung EV. Chronic lateral elbow instability. Orthop Clin North Am. 2008;39:221-228.

10. Cohen MS. Lateral collateral ligament instability of the elbow.
Hand Clin. 2008;24:69-77.

11. Conway JE, Jobe FW, Glousman RE, Pink M. Medial instability of the elbow in throwing athletes. Treatment by repair or reconstruction of the ulnar collateral ligament. J Bone Joint Surg Am. 1992;74:67-83.

12. Ebrahimzadeh MH, Amadzadeh-Chabock H, Ring D. Traumatic elbow instability. J Hand Surg Am. 2010;35:1220-1225.

13. Grace SP, Field LD. Chronic medial elbow instability. Orthop Clin North Am. 2008;39:213-219.

14. Finkbone PR, O'Driscoll SW. Box-loop ligament reconstruction of the elbow for medial and lateral instability. J Shoulder Elbow Surg. 2015;24:647-654.

15. Padulo J, Oliva F, Frizziero A, Maffulli N. Muscles, Ligaments and Tendons Journal - Basic principles and recommendations in clinical and field science research: 2016 update. MLTJ. 2016;6(1):1-5.

16. O'Driscoll SW, Morrey BF, Korinek S, An KN. Elbow subluxation and dislocation. A spectrum of instability. Clin Orthop Relat Res. 1992;280:186-197.

17. Hollinger B, Dehlinger F, Franke S. Diagnostik und Therapie der ligamentären Ellenbogeninstabilitäten. Obere Extremität. 2014;9:147-155.

18. O'Driscoll SW. Classification and evaluation of recurrent instability of the elbow. Clin Orthop Relat Res. 2000;370:34-43.

19. Van Riet RP, Bain Gl, Baird R, Lim YW. Simultaneous reconstruction of medial and lateral elbow ligaments for instability using a circumferential graft. Tech Hand Up Extrem Surg. 2006;10:239-244.

20. van Riet RP, Lim YW, Baird R, Bain Gl. Ligamentous reconstruction of the elbow in a 13-year old using a circumferentia technique. Injury Extra. 2008;39:256-259. 